\title{
Dermatology residency research policies and support: A national USA survey
}

\section{Pratibha Anand, Mindy Szeto, Hania Flaten, Cory Dunnick, Robert Dellavalle}

\author{
University of Colorado School of Medicine, 13001 E 17 th Pl, Aurora, CO 80045, USA
}

Corresponding author: Dr. Pratibha Anand, E-mail: pratibha.anand@cuanschutz.edu

\begin{abstract}
Background: Dermatology residency programs are considerably varied in regard to their resident research requirements and resources. The authors examined the availability of 12 key resident research-related criteria in 30 ACGME dermatology residency programs in the United States. Objective: To assess the degree to which dermatology residency programs require and support their new physician graduates in scholarly research. Methods: This cross-sectional study employed a 12-item survey administered online that was informed and created by literature search, expert feedback, and a thorough review and revision process. The primary purpose of the study was to examine the differences in programs' policies and structure around resident research. Results: Thirty out of 114 PDs (26\%) responded to the survey. We found that while most programs had publication and QI project requirements for residents, the majority did not have required research rotations, research electives, or a formal mentorship program. Thus, in spite of a growing need for new physician-scientists coupled with the various benefits associated with conducting research during residency training, considerable hurdles dissuade new physician graduates from pursuing careers in clinical research. Conclusions: Our survey findings supply timely, objective data on dermatology resident research requirements across the country. Medical schools, residency programs, and the ACGME/ AMA may all find our results valuable in further enhancing, evolving, and systematizing dermatology residency policies and provisions.
\end{abstract}

Key words: Dermatology, Residency, Survey, Research, ACGME

\section{INTRODUCTION}

The dermatology residency is one of the most competitive residencies available to medical school students. Applicants who successfully matched into dermatology have the second highest mean USMLE Step 1 scores across all residency applicants [1]. Over 1,000 Dermatology applicants applied to an average of 82.2 programs. Over half of them were AOA members and over $40 \%$ graduated from one of the top 40 medical schools in the United States based on NIH funding. Finally, applicants who matched into Dermatology had a mean number of 11.7 abstracts, presentations, and publications; 10.1 volunteer experiences; and 4.7 research experiences [1].

In contrast to the highly structured application process, Dermatology programs themselves vary widely in their features, approaches, demographics, and requirements for research. A minority of Dermatology residency programs have formally allotted time devoted to research within their curricula, and many programs' requirements for research are much broader and more open-ended [2].

The specific research requirements associated with Dermatology residency programs is poorly characterized in the literature, as far as we are aware. Given the heterogeneity of residency programs and the competitiveness in their selection criteria, attaining an improved characterization of program research requirements would be influential and important to applications and Dermatology programs alike. Indeed, research within other medical specialties indicates that prospective applicants consider a variety of factors

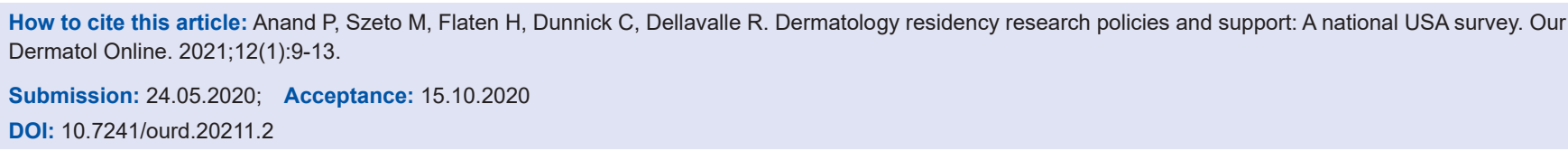


when ranking residency programs, not limited to their reputation, geographical location, or personal interactions $[3,4]$.

Our study aimed to collect data about and categorize the similarities and differences between research requirements and expectations amongst Dermatology Residency Programs in the United States [5-8]. Elucidating these mutable and heterogeneous factors has the potential to aid residency programs in emphasizing unique and distinguishing characteristics of their program and attracting the most competent candidates. Meanwhile, our study provides a foundation to pave the way for greater transparency and even standardization of requirements amongst programs.

\section{MATERIALS AND METHODS}

\section{Questionnaire Development and Dissemination}

Our study was a cross-sectional survey utilizing a categorical, study-specific online questionnaire. Our initial draft was formulated subsequent to a review of the relevant published literature utilizing PubMed. The survey was subsequently assessed and edited by the authors as well as a team of content experts including Dermatologists, Dermatology PDs, and medical school students.

Our study was developed using the REDCap platform. We chose to use the REDCap application as it is HIPAA-compliant, user-friendly, and can be used to collect virtually any type of data. It is further optimized to be able to support both online and offline data capture for research.

Our study obtained Not Human Subjects Research IRB approval (COMIRB \# 17-1634) from the University of Colorado, Denver, Institutional Review Board. It was exempt from the requirements of written consent due its nature of being a survey.

In addition to collecting demographic data, our final survey (Appendix I) contained 12 items including 11 yes/no questions and 1 numerically-coded question asking respondents how many days off per year residents in their program have to attend academic events such as research symposia or professional conferences. All "yes" responses was givens space to elaborate.

All 114 Accreditation Council for Graduate Medical Education (ACGME) approved dermatology programs were eligible in our study. Contact information for the programs was gathered and organized via a structured search in the ACGME, American Medical Association (AMA), American Academy of Dermatology (AAD) websites. Contact information for those programs whose contact information was unavailable or found to be no longer in use after consulting these sources was retrieved directly from individual program websites.

Our survey was sent to each program via an email that outlined our study's objectives and contained a secure and specific URL link to the survey. Emails were sent between January 2018 and November 2018. Programs that did not respond to our initial request for completion were contacted again an average of 3 times. Data were downloaded from the REDCap database and analyzed as survey responses were gathered.

\section{Outcomes and Objectives}

The primary aim of our study was to characterize the differences in the standards and specifications of dermatology residency research requirements (if present) between individual programs. Our criteria included requirements for publication, QI projects, and research rotations, as well as the availability of research electives, funding for AAD Annual Meeting attendance, research mentors, and the presence of a formal written statement describing the program's policies regarding resident research and conference attendance.

The secondary outcome of our study was to assess the nature of these program differences and to categorize and systematize our findings for possible future use by and benefit for the ACGME, residency programs, and prospective applicants alike.

\section{RESULTS}

We collected a total of 30 responses to our questionnaire. The majority of respondents $(n=19)$ reported having publication requirements for their residents. An even larger proportion of respondents $(n=23)$ reported having Quality Improvement (QI) requirements for residents. On the other hand, only 3 respondents reported having a required research rotation for residents, while just 11 respondents reported even offering a research elective option.

Meanwhile, though 25 programs reported having a written statement outlining program policies on 
resident research and conference attendance, only 7 programs allotted 10 or more days for residents to attend academic events such as research symposia or professional conferences. Despite this finding, 26 programs reported having funding allocated for residents to attend the AAD Annual meeting as well as participate in other conferences or educational activities.

Interestingly, even though most programs reported financially supporting conference and meeting attendance, close to half of the programs surveyed $(n=11)$ reported lacking funding for residents to present research at these events. Even more programs $(\mathrm{n}=19)$ reported lacking a formal mentorship program to connect residents with research mentors. Nevertheless, all but 1 program report research mentor access for residents.

\section{DISCUSSION}

Research from numerous specialties have described the nature of research and research policies during residency training [9-12]. In contrast to most other specialties prior to the implementation of strict duty-hour rules in 2003 [13], dermatology residency programs have historically been structured to be able to support research activities.

There are myriad advantages associated with research during residency. Residents' research may result in improved patient care by cultivating clinical reasoning, critical appraisal skills, and lifelong learning $[14,15]$. Since publication during residency is associated with careers in academic medicine [16], research during postgraduate training may also help bolster the declining numbers of clinician investigators [17]. Publication and presentation of research by interns may also improve the reputation of residency programs, allowing them to draw more competitive applicants $[18,19]$. Lastly, research experience during residency is beneficial to residents applying for jobs or fellowships [20].

In spite of the various advantages associated with research during residency, our findings suggest that program policies, procedures, structure, and support concerning resident research is highly variable.

Even though there is a growing need for new physicianscientists, considerable hurdles dissuade new physician graduates from pursuing careers in clinical research.
Physicians who are considering research careers weigh mounting financial challenges against the unpredictability of decreased federal research budgets and insufficient mentorship opportunities [21-23]. As a result, morale among aspiring investigators is deteriorating, with many choosing to give up their research interests in order to pursue full-time clinical careers $[24,25]$.

Though much has been done to expand research exposure and training for medical students and fellows, there are a scant number of formal programs specifically designed to target resident physicians. It is probable that residency was deemed too busy to accommodate research, due to its demanding schedule and emphasis on clinical training and subspecialty selection. The formidable growth of technology, data, and medical innovations needed to be mastered during residency in the current healthcare setting, coupled with higher acuity, shorter hospital stays, and growing patient turnover, has only heightened the challenge. The ongoing demands to reduce "length of stay" may also have the unintended consequence of deterring some residents from pursuing careers in research by compromising scientific inquiry into their patients' health conditions due to the focus on patient "disposition" [13].

Adding to these challenges is the trend towards greater reliance on hospitalists as attending physicians on inpatient wards at teaching hospitals. This trend may improve clinical care but almost always reduces residents' exposure to researchers who can serve as potential mentors [26]. Residency in the time in which most graduates are finalizing their career trajectories; thus, this lack of exposure during residency is likely to result in a dearth of researchers in the future. The ultimate impact of these trends has yet to be fully realized and is particularly worrisome, given healthcare's move towards more precise and fasterpaced care delivery and technological innovation [13].

Authors have described research curricula or research rotations, but there is a paucity of empirical studies describing specific components of an effective resident research program. Previous surveys suggest that residents [25] report lacking both interest in and time for research. Our study adds to this body of literature by revealing that the majority of dermatology program directors surveyed report a lack of research requirements, curricula, guidelines, mentors, and funding as further barriers to research. 
Some study limitations should be taken into account. First, our sample size was limited to roughly one quarter $(26.3 \%)$ of all ACGME Dermatology residency programs. Our findings may thus not be representative of all programs and should not be used to draw conclusions about programs that were not surveyed. Nevertheless, our respondents included programs from all geographical regions of the United States, including several top 20 medical schools [27]. Second, while we left room for respondents to elaborate, not all participants responded to all of the open-ended questions, and the degree of clarification or description provided was highly variable.

Finally, it is important to keep in mind that our data represents programs of various types. We report average findings for a sample that included private, public, highly endowed, government-run, urban, rural, large, and small institutions.

\section{CONCLUSION}

According to the Accreditation Council for Graduate Medical Education (ACGME), graduate medical education should occur in "an environment of inquiry and scholarship in which residents participate in the development of new knowledge, learn to evaluate research findings, and develop habits of inquiry as a continuing professional responsibility." The Residency Review Committees (RRCs) of the ACGME specifically require that interns participate in scholarly activity such as original research, reviews of research, or case reports during their residency training [28]. Insufficient evidence of residents' scholarship is one of the most common causes that residency programs are cited by the RRC [29].

Conducting research during residency can be very challenging. Studies suggests that successful research training include the following elements: (1) designated research time; (2) training in basic research methods; (3) the availability and guidance of mentors; and (4) an environment that encourages research participation [30-32]. We found that several of these factors were included in the programs we surveyed.

Nevertheless, our survey suggests that many dermatology residency programs lack some or all of the necessary infrastructure and resources required to adequately and effectively support research among their residents. Our findings add to the extant body of literature that describes residency research rotations and curricula and can inform future research and interventions designed to address research deficiencies among programs.

In sum, the mandate for resident research has the potential to enhance the practice of medicine, improve quality, and reduce cost. However, for research to take place on a large scale, residency training programs must surmount various significant hurdles. Effective implementation demands a thoughtful methodology that focuses on overcoming specific barriers, starting with institutional culture change to foster an environment of inquiry and the financial investment to create the infrastructure needed to support the research endeavors.

\section{Statement of Human and Animal Rights}

All procedures followed were in accordance with the ethical standards of the responsible committee on human experimentation (institutional and national) and with the Helsinki Declaration of 1975, as revised in 2008 .

\section{Statement of Informed Consent}

Informed consent was obtained from all patients for being included in the study.

\section{REFERENCES}

1. Liang M. National Resident Matching Program and Association of American Medical Colleges, Charting Outcomes in the Match: Characteristics of Applicants Who Matched to their Preferred Specialty in the 2018 Main Residency Match. 2nd ed. Washington, DC: National Resident Matching Program. 2018.

2. Wagner RF, Raimer SS, Kelly BC. Incorporating resident research into the dermatology residency program. Adv Med Educ Pract. 2013;4:77-81.

3. Huntington WP, Haines N, Patt JC. What factors influence applicants' rankings of orthopaedic surgery residency programs in the National Resident Matching Program? Clin Orthop Relat Res. 2014;472:2859-66.

4. Marciani RD, Smith TA, Heaton LJ. Applicants' opinions about the selection process for oral and maxillofacial surgery programs. J Oral Maxillofac Surg. 2003;61:608-14.

5. Gorouhi F, Alikhan A, Rezaei A, Fazel N. Dermatology residency selection criteria with an emphasis on program characteristics: a national program director survey. Dermatol Res Pract. 2014;2014:1-8.

6. Tuong W, Fazel N, Eisen DB. Factors influencing applicants' ranking of dermatology residency programs in the national resident matching program. JAMA Dermatol. 2015; 151:1378-80.

7. Wu JJ, Ramirez CC, Alonso CA, Mendoza N, Berman B, Tyring SK. Dermatology residency program characteristics that correlate with graduates selecting an academic dermatology career. Arch Dermatol. 2006;142:845-50.

8. Freeman SR, Greene RE, Kimball AB, Freiman A, Barzilai DA, Muller S, et al. US dermatology residents' satisfaction with training and mentoringsurvey results from the 2005 and 2006 Las Vegas Dermatology Seminars. Arch Dermatol. 2008;144:896-900.

9. Kanna B, Deng C, Erickson SN, Valerio JA, Dimitrov V, Soni A. 
The research rotation: competency-based structured and novel approach to research training of internal medicine residents. BMC Med Educ. 2006;6:52.

10. Boninger ML, Chan L, Harvey R, Pine ZM, Helkowski W, Garrison CJ, et al. Resident research education in physical medicine and rehabilitation: a practical approach. Am J Phys Med Rehabil. 2001;80:706-12.

11. Segal LS, Black KP, Schwentker EP, Pellegrini VD. An elective research year in orthopaedic residency: how does one measure its outcome and define its success? Clin Orthop Relat Res. 2006;449:89-94.

12. Vinci RJ, Bauchner H, Finkelstein J, Newby PK, Muret-Wagstaff S, Lovejoy FH., Jr. Research during pediatric residency training: outcome of a senior resident block rotation. Pediatrics. 2009;124:1126-34.

13. Oxnard GR, Zinkus TM, Bazari H, Wolf M. Integrating research training into residency: tools of human investigation. Acad Med. 2009;84:1295-300.

14. Abramson M. Improving resident education: What does resident research really have to offer? Trans Sect Otolaryngol Am Acad Ophthalmol Otolaryngol. 1977;84:984-5.

15. Goodman, N. Does research make better doctors? Lancet. 1994;343:59.

16. Hillman BJ, Fajardo LL, Witzke DB, Cardenas D, Irion M, Fulginiti JV. Factors influencing radiologists to choose research careers. Invest Radiol. 1989;11:842-8.

17. Rosenberg LE. Young physician-scientists: internal Medicine's challenge. Ann Intern Med. 2000;133:831-2.

18. Heinrich G, Nori D, Tome J, Parikh S. Developing a research program in a community teaching hospital. Teach Learn Med. 1999;2:89-93.

19. Schultz HJ. Research during internal medicine residency training: meeting the challenge of the residency review committee. Ann Intern Med. 1996;124:340-2.

20. Souba WW, Tanabe KK, Gadd MA, Smith BL, Bushman MS. Attitudes and opinions toward surgical research. A survey of surgical residents and their chairpersons. Ann Surg. 1996;223:377-383.

21. Wolf M. Clinical research career development: The individual perspective. Acad Med. 2002;77:1084-8.

22. Rosenberg LE. The physician-scientist: An essential—and fragilelink in the medical research chain. J Clin Invest. 1999;103:1621-6.

23. Nathan DG. Clinical research: Perceptions, reality, and proposed solutions. National Institutes of Health Director's Panel on Clinical Research. JAMA. 1998;16:1427-31.

24. Shulman LE. Clinical research 1996: Stirrings from the academic health centers. Acad Med. 1996;71:362-3, 398.

25. Thompson JN, Moskowitz J. Preventing the extinction of the clinical research ecosystem. JAMA. 1997;278:241-5.

26. Kralovec PD, Miller JA, Wellikson L, Huddleston JM. The status of hospital medicine groups in the United States. J Hosp Med. 2006;1:75-80.

27. Morse R, Hines K, Martin E. 2020 Best Medical Schools. Washington, DC: U.S. News and World Report. 2019.

28. Accreditation Council for Graduate Medical Education. ACGME Common Program Requirements. Chicago, IL: Accreditation Council for Graduate Medical Education. 2017.

29. Beasley BW, Scrase DR, Schultz HJ. Determining the predictors of internal medicine residency accreditation: what they do (not what they say). Acad Med. 2002;77:238-46.

30. Bland CJ, Schmitz CC. Characteristics of the successful researcher and implications for faculty development. J Med Educ. 1986;61:22-31.

31. Bland CJ, Ruffin MT. Characteristics of a productive research environment: literature review. Acad Med. 1992;67:385-97

32. Temte JL, Hunter PH, Beasley JW. Factors associated with research interest and activity during family practice residency. Fam Med. 1994;26:93-7.

Copyright by Pratibha Anand, et al. This is an open-access article distributed under the terms of the Creative Commons Attribution License, which permits unrestricted use, distribution, and reproduction in any medium, provided the original author and source are credited.

Source of Support: Nil, Conflict of Interest: None declared. 